\title{
Three-Phase Isolated Multi-Modular Converter in Renewable Energy Distribution Systems
}

\author{
Cristian Verdugo, Student Member, IEEE, Jose Ignacio Candela, Member, IEEE, Frede Blaabjerg, Fellow, IEEE, \\ and Pedro Rodriguez, Fellow, IEEE
}

\begin{abstract}
Multilevel converters are widely used in medium and high voltage applications. Their high performance, power quality, efficiency and smaller filters make them interesting for renewable energy distribution systems. In utility- scale photovoltaic plants, these topologies could provide multiple benefits since they are able to connect string of photovoltaic panels to independent modules. However, high floating voltages caused by high number of modules limit multilevel converters in medium and high voltage applications, since all of them are not suitable to provide isolation to each module. To offer a solution, this paper presents a novel multi-modular converter that provides multiple isolated modules connected in series through low frequency transformers to operate at medium voltage levels. This topology is able to achieve the power balancing between the connected modules and independently adjust the dc voltage of each module by means of controlling a circulating current which flows through the arms. Furthermore, the topology implemented in photovoltaic renewable energy systems and the control strategy required to regulate the circulating and the output current are presented. The main principle behind this concept and the performance of the converter are evaluated and validated through simulation and experimental results.
\end{abstract}

Index Terms-Cascaded Transformer Multilevel Inverter, High voltage systems, Isolated Multi-Modular Converter, Modular Multilevel Converter

\section{INTRODUCTION}

$\mathbf{I}$ $\mathrm{T}$ is a fact that Renewable Energy Sources (RES) are the best substitute for electric energy generation and it is expected that they continue growing in the next years [1]. In terms of installed power, wind and photovoltaic (PV) are the most used RES around the world, due to the advantages that they offer in terms of accessibility, capability, and levelized cost of energy [2]. However, both technologies have some features that introduce remarkable differences between them, especially in high power applications. For instance, multiMW wind energy systems are connected to medium voltage networks in onshore and offshore plants without isolation issues [3], on the other hand, PV systems are always connected to low voltage networks due to the fact that current constraints

Manuscript received July 25, 2018; revised September 06, 2018; accepted January 16, 2019. This work has been supported by the Spanish Ministry of Economy and Competitiveness under the projects ENE2016-79493-R and ENE2017-88889-C2-1-R.

C. Verdugo and J. Candela are with the Electrical Engineering Department, Technical University of Catalonia (UPC), 08222 Barcelona, Spain, e-mail: cristian.andres.verdugo@upc.edu

F. Blaabjerg is with the Center of Reliable Power Electronics, Department of Energy Technology, Aalborg University, 9100 Aalborg, Denmark..

P. Rodriguez is with the Department of Engineering, Loyola University Andalusia, 41014 Seville, Spain, and also with the Electrical Engineering Department, Technical University of Catalonia (UPC), 08222 Barcelona, Spain in the voltage insulation of PV panels do not permit operating beyond $1500 \mathrm{~V}$ [4].

In the last few years, multilevel converters have been used in a wide number of applications related to the renewable energy sector [5], as they permit to achieve high power quality rates working at low switching frequencies, managing a high number of voltage levels, reducing switching losses, optimizing the output filters and minimizing the $d v / d t$ at the ac side [6]. Some multilevel converters such as the one based on Neutral Point Clamped (NPC) concept [7] or Flying Capacitors (FC) [8] have a main dc bus which is internally split into three or more voltage levels. On the other hand, multi-cells or multi-modular converters are a sub family of multilevel converters [5]. They consist of a series connection of modules that provides high degree of modularity. These converters permit to reduce the semiconductor stress, and the switching frequency without reducing the power quality. In medium and high voltage applications, Cascaded H-Bridge (CHB) [9] and Modular Multilevel Converters (MMC) [10], [11] are the most popular multilevel topologies.

Even though multi-cell converters could be an excellent option for large PV plants, voltage insulation constraints in PV panels limit such converters to operate at medium or high voltage levels. Due to this, some industrial configurations employ multi-cell converters with a reduced number of modules in order to operate at low voltage and low power rates [12].

Isolation constrains have motivated many researchers to look for solutions, therefore, several new configurations have been proposed. Converters with two conversion stages can be used to provide galvanic isolation in PV string, thus high floating voltage and leakage currents can be eliminated. In [13] a cascaded topology for utility-scale PV plants, using an isolated dc-dc stage was proposed. In such as configuration, the dc-dc stage consists of a boost half-bridge or a flyback converter with a high frequency transformer, which is responsible for tracking the maximum power point of the PV string. In [14] a MMC with integrated storage for photovoltaic applications in high voltage dc transmission networks was proposed. In such a topology, high frequency transformers were used to provide isolation between the PV panels and the converter modules. Despite the fact that these configurations are technically feasible for working at high voltage, the high associated costs would make them unfeasible for commercial applications.

Cascaded-Transformers Multilevel Inverters (CTMI) [15] are converters based on several H-Bridge modules connected to low-frequency transformers, whose secondary windings are 
connected in series. The H-Bridge modules have only one dc source and they employ cascaded low frequency transformers to increase the number of output voltage levels. This topology offers several advantages, such as: galvanic isolation between the ac and the dc side; reduced leakage currents; and the possibility of setting a certain transformer ratio to reach a desired voltage level [16]. Although, low frequency transformers are bulky and increase the total cost of the system, they are still required in many applications. Therefore, using CTMI in PV could be an advantageous and cost-effective overall solution. A CTMI topology based on single and three-phase transformers were proposed in [17]. In the suggested topology, H-bridge cells were used and the performance of the converter was compared with conventional converters. Likewise, a modified CTMI for photovoltaic applications was presented in [18]. Such topology reduces the number of switches in some cells by using a half bridge inverter connected to the midpoint of the dc source instead of full bridge inverters. Other works related to control strategies and validation of CTMI can be found in [19]-[22].

Even though the CTMI is an attractive configuration to be used in PV systems, the requirements for employing only one dc source limits its application when high power levels are required. Particularly, very high dc currents will appear when many PV strings are connected in parallel to generate high power levels.

In order to overcome the drawbacks presented above, such as: isolation and high floating voltage concerns, this paper proposes and validates a new topology based on the CTMI and the MMC. The proposed converter, called Three-Phase Isolated Multi-Modular Converter (3-IMMC) introduced previously in [23], counts on two arms with several three phase modules to split the power generated. Both arms are connected in parallel through coupling inductances which represent the equivalent winding inductances in the series connection of transformers. Since each PV string is connected to an isolated module, the converter can be used in medium or high voltage applications. Moreover, an ac circulating current is employed to handle unbalanced power conditions.

The rest of the paper is organized as follows: In section II, the foundation of utility-scale PV plants is introduced. Section III presents the model of the IMMC, where the dynamic and the average dc voltage model are studied considering the single-phase electrical circuit. In section IV, a control strategy is proposed to regulate the power delivered to the grid and the power unbalance between the modules. In section V, the performance of the proposed converter is validated with simulation results. In order to match with the experimental test bench used, the simulation model implements two modules per arm which operate at different power levels. In section VI, the technical aspects of the proposal are validated through experimental results, where a three phase converter represents the series connection of modules per arm. Finally, section VII concludes the paper.

\section{Utility-Scale PV Plants}

Large scale PV plants can be found in two different configurations: central configuration and multi-string configuration.

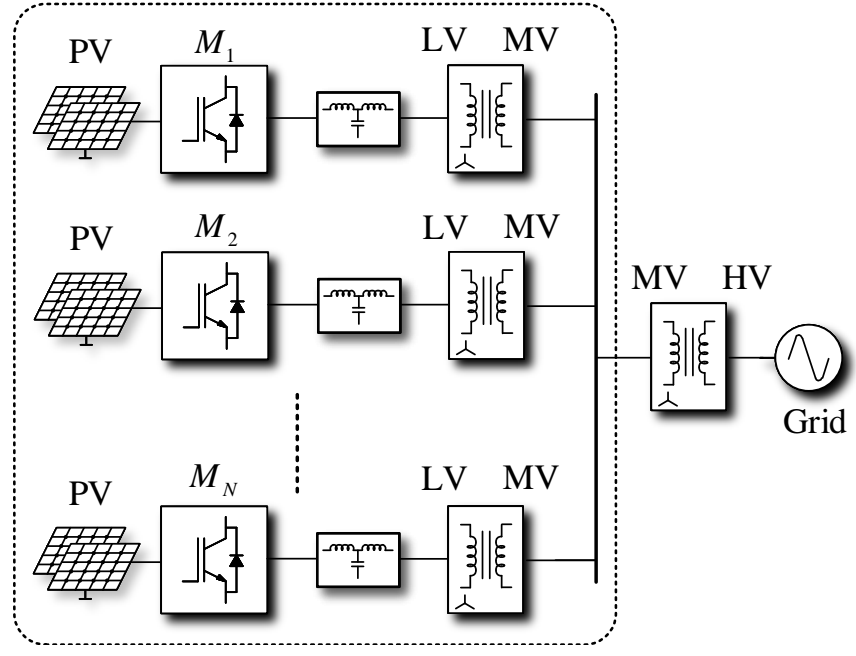

Fig. 1. Standard PV plant based on central inverters.

The first one, integrates a single three-phase voltage source converter connected to the PV plant. The grid integration is performed through low frequency transformers which serve for voltage elevation and galvanic isolation. Multi-string configurations have a distributed structure, where several dcdc converters provide independent MPPTs [24]. The dc-dc converters are connected to a common dc bus-bar and then a central inverter transforms the dc to ac signals. Even though, both configurations can be found in current PV plants, the high robustness, low ac power losses and simple structure, make the central configuration the most widely used for utility-scale PV plants.

Since the central configuration is the preferred technology used in PV large scale systems, the Isolated Multi-Modular Converter arises as a result of low frequency transformers connected to three-phase voltage source converters. A typical utility-scale PV plant is shown in Fig.1, this configuration has several central inverters located next to low frequency transformers which elevate the ac voltage from low to medium voltage levels and connect them to an ac collector. Usually, ac collectors operate between 2.3 to $35 \mathrm{kV}$ and are connected to the transmission line through a substation where a transformer elevates from medium to high voltage levels.

Compared to the central configuration, the series connection of modules in the IMMC increases $N$ times the ac voltage. Therefore, higher voltage and smaller current levels can be achieved in the ac bus-bar (small power losses in the ac cables). This feature also allows smaller conversion ratios to achieve a desired voltage level in the MV side of the transformer. In addition, an appropriate modulation technique can increases the number of output voltage levels, mitigates the current ripple and reduces the $d v / d t$.

The IMMC merges several central inverters in one single unit. Therefore, it requires a complex control strategy and a reliable communication system to control all modules and at the same time, provides the proper references from the central controller. In the next section a description about its operation and control strategy are presented. 


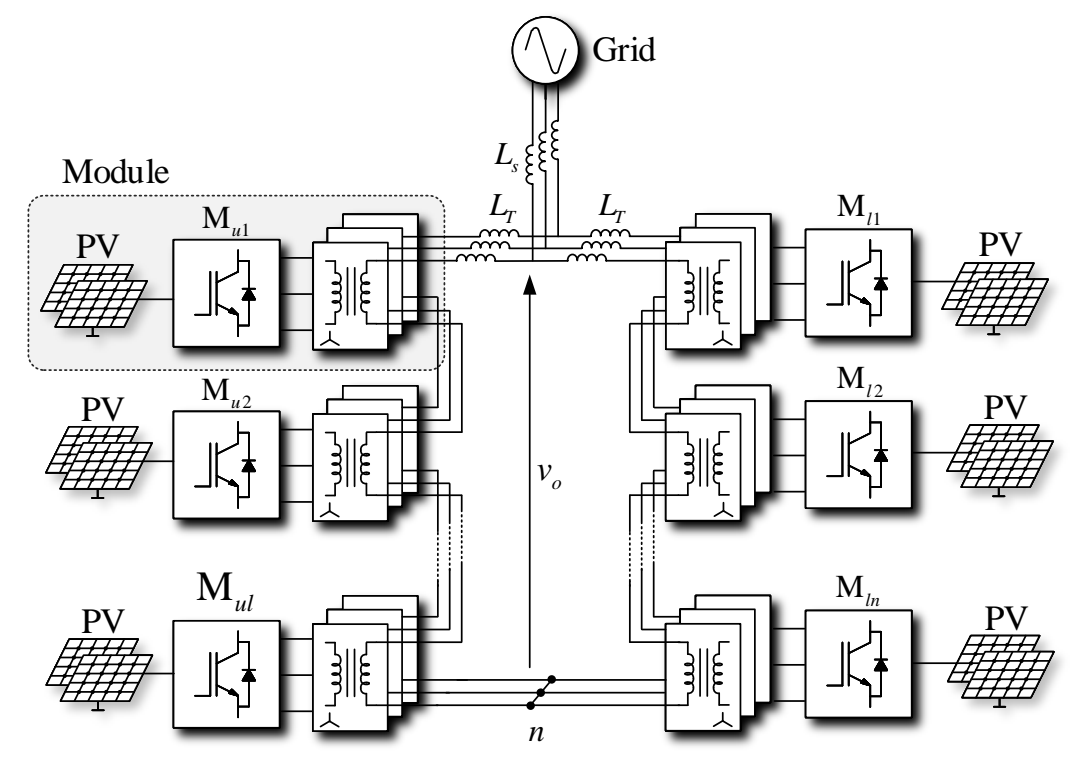

Fig. 2. Three Phase Isolated Multi-Modular Converter.

\section{Three-Phase Isolated Multi-Modular CONVERTER}

The insulation properties of some dc sources limit their application in multi-cell converters. Because of this, modules with galvanic isolation provided by high or low frequency transformers are required to avoid high floating voltages. In order to overcome this problem, the proposed configuration shown in Fig.2 is composed of two arms with $N$ three phase converter modules, which are electrically interconnected through the secondary winding of several transformers. These transformers provide the isolation needed to eliminate the insulation concern. The module can be built using Two Level Voltage Source Converters (2L-VSC) or any other configuration, such as NPC or Three Phase T-Type Converters [25].

The upper and the lower arms are connected in parallel between a common neutral point $n$ and a coupling inductance. In Fig.2, $L_{T}$ represents the equivalent inductance between the transformer windings and the line filter, which is used for reducing the current ripple. The output voltage $v_{o}$ measured between the parallel connection is controlled through the current injected into the grid. It is worth remarks that, due to the parallel connection and the possibility of unbalanced power injection, a circulating current may arise. Therefore, in order to maintain the power balance among all modules, the circulating current as well as the grid current has to be controlled.

\section{A. Dynamical Model}

To verify the IMMC operation, the dynamical model can be studied from the equivalent electrical circuit. The circuit shown in Fig.3 represents a single phase model, where one arm is composed of $N$ controlled voltage sources in series with a coupling inductance $L_{T}$ and an equivalent resistor $R_{T}$. The voltage sources modulate the dc voltage of each module, while $R_{T}$ represents the power losses in both arms. The output voltage $v_{g}$ generated by the parallel connection between the arms is connected to the ac grid $v_{g}$ through an equivalent grid impedance of $R_{g}$ and $L_{g}$.

In order to simplify the model, the output voltage of each module is added to obtain the average voltage per arm, which can be represented according to:

$$
v_{i}=\sum_{k=1}^{N} v_{i, k}
$$

Where $i$ is the upper or lower arm, and $k$ is the number of module. Considering the $2 \mathrm{~L}-\mathrm{VSC}$ as the topology used in all modules, the equivalent output voltage can be written as:

$$
v_{i, k}=\frac{V_{d c, i, k}}{2} m_{i, k}
$$

Where $m_{i, k}$ is the modulation index and $V_{d c, i, k}$ is the dc voltage in the module $k$ [26]. Since different dc voltage levels may arise in the series connection of modules, it is necessary to implement an accurate voltage balancing control to regulate these dc voltage differences. Just like the MMC model studied in [27], to determine the IMMC model, it is considered that all modules operate at the same dc voltage level. Therefore, the average voltage per arm presented in (1) can be defined according to the expression (2), where the output voltage is replaced by:

$$
v_{i}=\frac{V_{d c}^{\sum}}{2 N} \sum_{k=1}^{N} m_{i, k}
$$

Where $V_{d c}^{\sum}$ represents the sum of all dc voltages in one arm. Furthermore, the modulation index can be simplified according to its average value by:

$$
m_{i}=\frac{1}{N} \sum_{k=1}^{N} m_{i, k}
$$




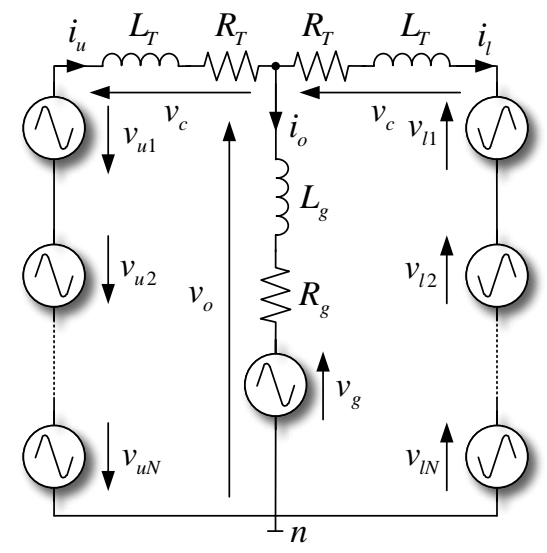

Fig. 3. Electric model of the Isolated Multi-Modular Converter.

The current in the upper $\left(i_{u}\right)$ and the lower arm $\left(i_{l}\right)$ depends on the power delivered to the grid and the power difference between the arms. According to the Kirchhoff's current law definition in Fig.3, these currents can be represented by means of the output $\left(i_{o}\right)$ and the circulating current $\left(i_{c}\right)$.

$$
\begin{aligned}
& i_{o}=i_{u}-i_{l} \\
& i_{c}=\frac{i_{u}+i_{l}}{2}
\end{aligned}
$$

The circulating current comes up when power unbalances between modules take place. According to the previous expression, this current flows through the arms without having any influence in the output current and it becomes bigger when the power difference between the arms increases. Otherwise, when there is no power difference, the circulating current is zero.

According to the Kirchhoff's voltage law definition in Fig.3, the dynamic model of the upper and the lower arm are:

$$
\begin{aligned}
R_{T} i_{u}+L_{T} \frac{d i_{u}}{d t} & =-v_{u}-v_{o} \\
R_{T} i_{l}+L_{T} \frac{d i_{l}}{d t} & =v_{o}-v_{l}
\end{aligned}
$$

Where the drop voltage in $R_{T}-L_{T}$ can be represented by $v_{c}$. Replacing the current arms in the previous expressions, the dynamic model can be expressed by:

$$
\begin{aligned}
\frac{R_{T}}{2} i_{o}+\frac{L_{T}}{2} \frac{d i_{o}}{d t} & =\underbrace{\frac{-v_{u}+v_{l}}{2}}_{v_{s}}-v_{O} \\
R_{T} i_{c}+L_{T} \frac{d i_{c}}{d t} & =-\underbrace{\frac{\left(v_{u}+v_{l}\right)}{2}}_{v_{c}}
\end{aligned}
$$

The voltage $v_{s}$ governs the output current $i_{o}$ through the voltage difference between the arms. Meanwhile, the dynamic response of $v_{c}$ governs the circulating current $i_{c}$. Since these voltages depend on $v_{u}$ and $v_{l}$, an accurate control of the voltage arms is required. This requirement is achieved through the modulation index in the upper and the lower arm.

$$
\begin{gathered}
m_{u}=\frac{2}{V_{d c}^{\sum}}\left(v_{c}-v_{s}\right) \\
m_{l}=\frac{2}{V_{d c}^{\Sigma}}\left(v_{c}+v_{s}\right)
\end{gathered}
$$

It must be noted that the previous expressions require the sum of all $V_{d c}^{\sum}$ modules.

\section{B. Average Voltage Model}

The average dc voltage is defined by the energy stored in the arms, which depends on the power difference between the input and the output power. If the power losses are neglected, the power balance of one arm can be defined as:

$$
P_{o, i}=\sum_{k=1}^{N} P_{d c, i, k}-\sum_{k=1}^{N} P_{m, i, k}
$$

Where $P_{o, i}$ is the output power generated by the arm $i$, $P_{d c, i, k}$ is the input power and $P_{m, i k}$ is the instantaneous power in the module $k$. The instantaneous power can be represented as a function of the energy stored through the following expression:

$$
\sum_{k=1}^{N} P_{m, i, k}=\frac{d}{d t} \sum_{k=1}^{N} \frac{C_{m}}{2} V_{d c, i, k}^{2}
$$

Where $C_{m}$ is the dc capacitor. Now, by assuming that each module operates at the same dc voltage level, the previous equation can be replaced by:

$$
\begin{aligned}
\frac{d}{d t} \sum_{k=1}^{N} \frac{C_{s m}}{2} V_{d c^{2}, i, k} & =\frac{d}{d t} \sum_{k=1}^{N} \frac{C_{s m}}{2}\left(\frac{V_{d c, i}^{\sum}}{N}\right)^{2} \\
& =\frac{C_{s m}}{2 N} \frac{d}{d t}\left(V_{d c, i}^{\sum}\right)^{2}
\end{aligned}
$$

The model of the IMMC provides the basis for the control strategy by controlling the modulation index in the upper and the lower arm.

\section{Proposed Control Scheme}

The proposed control of the IMMC is shown in Fig.4. The control strategy is divided in two control blocks: the central control is responsible for regulating the absorbed or injected current to the grid as well as the circulating current produced by the unbalanced power between the arms. Even though, specific dc voltage references are set by each module, this control regulates the circulating and the output current from average dc values. Therefore, the central control does not differentiate between modules with higher or lower power. The second control block is required to adjust the dc voltage in each 


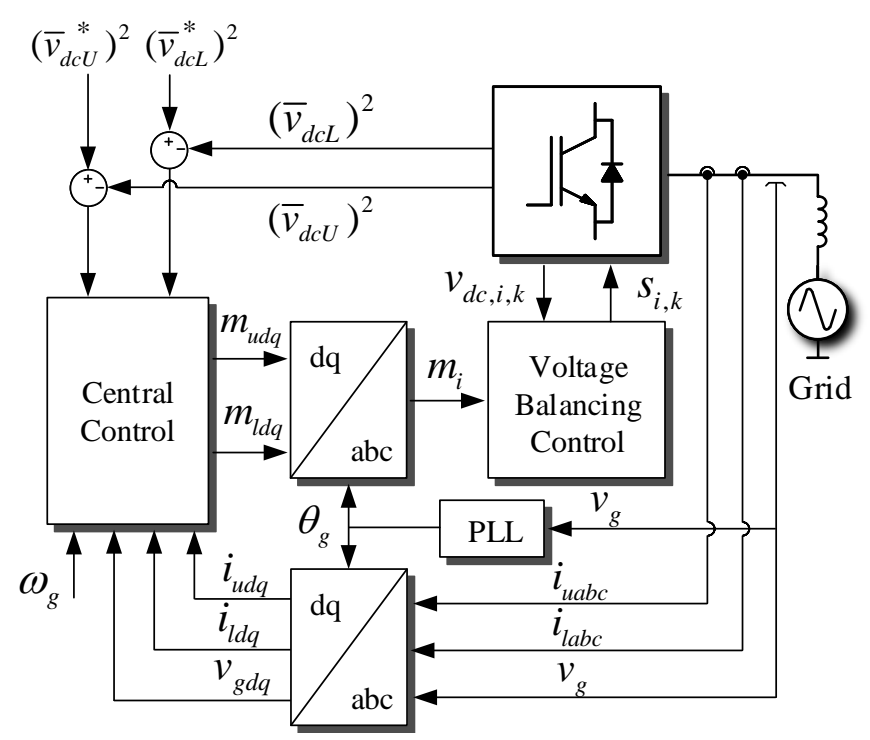

Fig. 4. General control scheme.

module, enabling the modules to operate at different power levels. The architecture of each control will be explained in the next subsections.

\section{A. Central Control}

The purpose of the central control is to generate $v_{s}$ and $v_{c}$ to regulate the general modulation index $m_{u}$ and $m_{l}$ and then, through the voltage balancing control adjust the modulation in each module. The schematic of Fig.5 shows its structure, where it can be seen how two inner control loops regulate the output and the circulating current through decoupled PI controllers. Both currents are transformed into the $d q$-frame components by means of a Phase-Locked-Loop (PLL) control [28] and synchronized with the ac grid to ensure unitary power factor. The $d$ frame component of the output and the circulating current reference are regulated by two external control loops which control the average dc voltage in both arms. According to (12), the average dc voltage reference is set by the addition of all dc references generated by each MPPT and divided by the number of modules connected in the arm. The output of these dc voltage controllers give rise to the instantaneous active power.

$$
\begin{aligned}
& v_{d c U}^{*}=\frac{1}{N} \sum_{k=1}^{N} v_{d c U, k}^{*} \\
& v_{d c L}^{*}=\frac{1}{N} \sum_{k=1}^{N} v_{d c L, k}^{*}
\end{aligned}
$$

The power balance between the $\mathrm{dc}$ and the ac side provides the relationship between the dc voltage and the output and circulating current. Neglecting the switching and conduction losses in the converter, the power generated is equal to the power delivered. Besides, considering an unitary power factor as a result of the synchronization control strategy, the instantaneous active and reactive power can be represented by (13), in which the $q$ component of the voltage is equal to zero

$$
\begin{aligned}
P_{i, k} & =\frac{3}{2} v_{i, k, d} i_{i d} \\
Q_{i, k} & =-\frac{3}{2} v_{i, k, d} i_{i q}
\end{aligned}
$$

The current $i_{i d}$ and $i_{i q}$ represent the direct and the quadrature current arms, which flow through the series connection of modules in the secondary winding of each transformer. Since the $d$ component is related to the active power, the total and the difference active power between $P_{T U}$ and $P_{T L}$ define the output and the circulating current $i_{o d}$ and $i_{c d}$. According to (1) and (13a), the total active power is represented by:

$$
\begin{aligned}
P^{\Sigma} & =P_{T U}+P_{T L} \\
& =\sum_{k=1}^{N} P_{u, k}+\sum_{k=1}^{N} P_{l, k} \\
& =\frac{3}{2}\left(\sum_{k=1}^{N} v_{u, k, d}\right) i_{u d}+\frac{3}{2}\left(\sum_{k=1}^{N} v_{l, k, d}\right) i_{l d} \\
& =\frac{3}{2}\left(v_{u d} i_{u d}+v_{l d} i_{l d}\right)
\end{aligned}
$$

The power $P_{T U}$ and $P_{T L}$ depend on the voltage $v_{i}$ and the current arm $i_{i}$. According to (6) and neglecting the drop voltage in the arm impedance, the voltage arm $v_{u}=-v_{o}$ and $v_{l}=v_{o}$. Therefore, the total power presented in (14) can be rewritten as:

$$
P^{\Sigma}=\frac{3}{2} v_{o d}\left(i_{l d}-i_{u d}\right)
$$

Additionally, replacing the output current expression presented in (5a), the output current reference $i_{o d}^{*}$ can be represented by:

$$
i_{o d}^{*}=-\frac{2 P^{\Sigma}}{3 v_{o d}}=P^{\Sigma} k_{o}
$$

Likewise the previous analysis, the $d$ component of the circulating current arises from the active power difference, which increases as the power difference between the arms becomes larger. According to the expressions (6) and (14), the active power difference is given by.

$$
\begin{aligned}
P^{\Delta} & =P_{T U}-P_{T L} \\
& =\sum_{k=1}^{N} P_{u, k}-\sum_{k=1}^{N} P_{l, k} \\
& =\frac{3}{2}\left(\sum_{k=1}^{N} v_{u, k, d}\right) i_{u d}-\frac{3}{2}\left(\sum_{k=1}^{N} v_{l, k, d}\right) i_{l d} \\
& =\frac{3}{2}\left(v_{u d} i_{u d}-v_{l d} i_{l d}\right)
\end{aligned}
$$




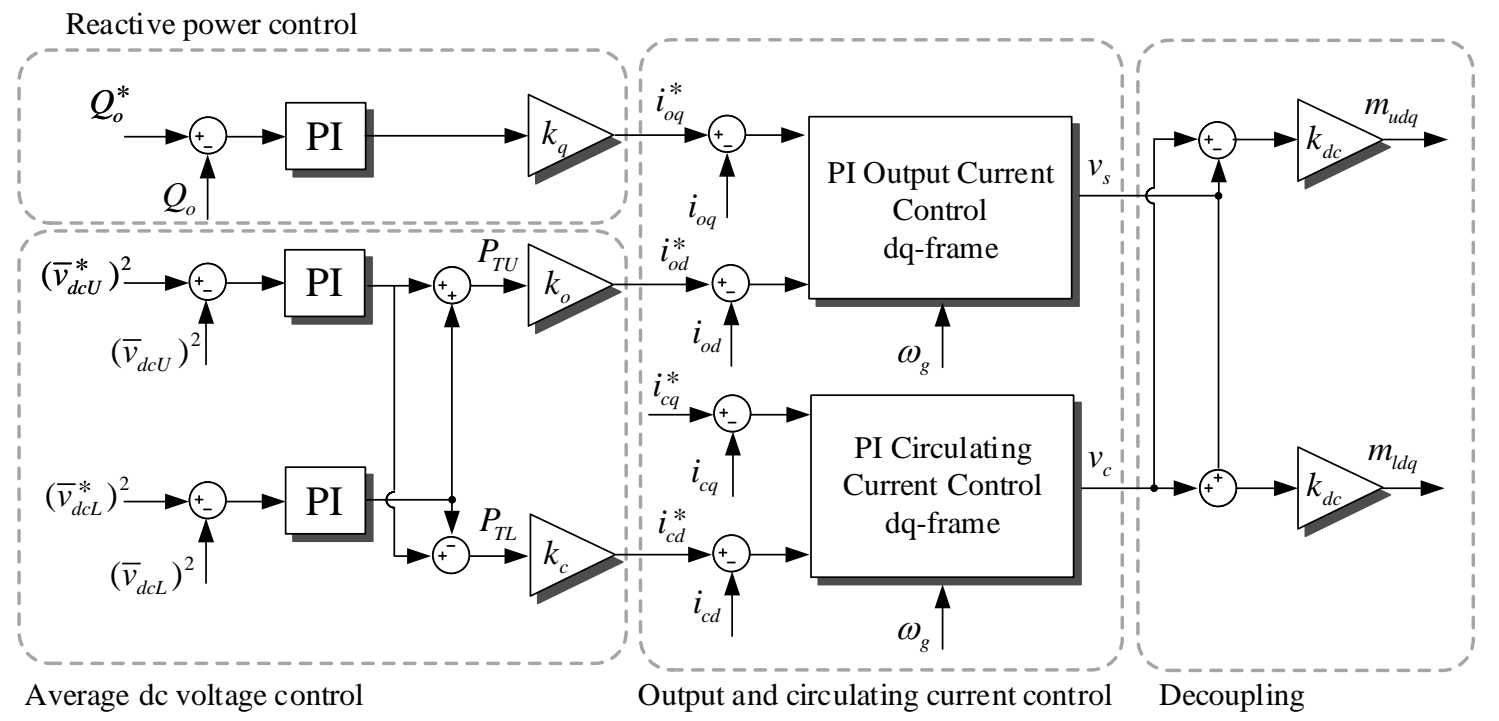

Fig. 5. Central control structure.

Replacing the voltage arm expressions in the output voltage, the circulating current reference $i_{c d}^{*}$ can be represented through the following expression.

$$
i_{c d}^{*}=-\frac{P^{\Delta}}{3 v_{o d}}=P^{\Delta} k_{c}
$$

Furthermore, the $q$ component of the output current depends on the reactive power control loop. In Fig.5, the reactive power difference is regulated through a PI controller and its output is turned into the output current reference through:

$$
i_{o q}^{*}=-\frac{2 Q}{3 v_{o d}}
$$

The $q$ component of the circulating current is used to control the power unbalance among modules of one arm. Since this paper includes a voltage control to compensate the modulation index amplitude, the circulating current reference $i_{c q}^{*}$ is set equal to zero. However, a further work will provide another control strategy relying on such circulating current component.

The output and the circulating current are regulated through inner current control loops. As previously mentioned, decoupled PI controllers are implemented according to the dynamic model presented in (7). The control parameters can be estimated as stated in [26] through the state space model represented by:

$$
\begin{aligned}
& \frac{d}{d t}\left[\begin{array}{l}
i_{o d} \\
i_{o q}
\end{array}\right]=\frac{1}{L_{T}}\left[\begin{array}{cc}
-R_{T} / 2 & \omega_{g} L_{T} \\
-\omega_{g} L_{T} & -R_{T} / 2
\end{array}\right]\left[\begin{array}{l}
i_{o d} \\
i_{o q}
\end{array}\right]+\left[\begin{array}{c}
v_{s d}-v_{o d} \\
v_{s q}
\end{array}\right] \\
& \frac{d}{d t}\left[\begin{array}{l}
i_{c d} \\
i_{c q}
\end{array}\right]=\frac{1}{L_{T}}\left[\begin{array}{cc}
-R_{T} & \omega_{g} L_{T} \\
-\omega_{g} L_{T} & -R_{T}
\end{array}\right]\left[\begin{array}{l}
i_{c d} \\
i_{c q}
\end{array}\right]-\left[\begin{array}{l}
v_{c d} \\
v_{c q}
\end{array}\right]
\end{aligned}
$$

The voltage $v_{s}$ and $v_{c}$ provided by the current control loops are decoupled and normalized through the modulation index expressions presented in (8), which are later used by the voltage balancing control to provide a sole modulation index.

\section{B. Voltage Balancing Control}

The voltage balancing control is a local control strategy introduced in each module to regulate independently the dc voltage. The proposed control based on [29] will not modify the central controller in any case, since the strategy adjusts the $d$-frame component of the average modulation index, which represents the voltage amplitude of $v_{i, k}$. The control structure implemented is presented in Fig.6

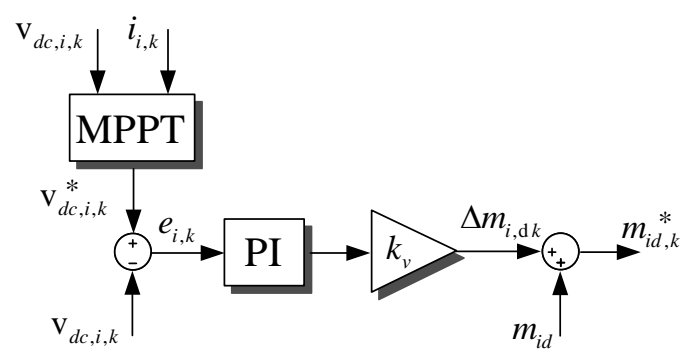

Fig. 6. Voltage balancing control scheme.

A MPPT algorithm provides the voltage reference according to the dc current and voltage measured in the dc side. A PI controller regulates the dc voltage difference through a compensation $\Delta m_{i, k}$ in the $d$ component of the modulation index. In the upper arm the compensation is added to $m_{u d}$, meanwhile in the lower arm, the compensation is subtracted from $m_{l d}$. In this way, modules with higher voltage will increase their modulation index amplitude and modules with lower voltage will decrease its amplitude. The new modulation index is represented by the following expression.

$$
\begin{aligned}
& m_{i d, k}^{*}=k_{v} \Delta m_{i d, k}+m_{i d} \\
& k_{v}=\left\{\begin{array}{rr}
1: & \text { Upper arm } \\
-1: & \text { Lower arm }
\end{array}\right.
\end{aligned}
$$


This control strategy does not required any new measurement, since the dc voltage is already available.

\section{Simulation Results}

The effectiveness of the proposed converter has been simulated with a discrete model in PSIM environment considering different scenarios. In the case of study, the converter has two modules per arm and two-level three phase inverters are implemented in each of them. A dc source connected in series to a $R_{d c}$ resistor represents the PV string characteristic between the open-circuit and the maximum power point operation. A small filter between the grid and the parallel connection of the arms is used to mitigate the switching frequency and to reduce the output current ripple. Simulation parameters are listed in the left side of Table.I.

TABLE I

Simulation AND EXPERIMENTAL PARAMETERS

\begin{tabular}{lcc}
\hline \hline Parameters & Symbol & $\begin{array}{c}\text { Value } \\
\text { Simulation | Experimenta }\end{array}$ \\
\hline Nominal Power & $P_{o}$ & $8 \mathrm{~kW} \mid 4 \mathrm{~kW}$ \\
Nominal Power per module & $P_{M}$ & $2 \mathrm{~kW}$ \\
Grid Voltage Amplitude & $v_{s}$ & $640 \mathrm{~V} \mid 320 \mathrm{~V}$ \\
Grid Frequency & $f_{s}$ & $50 \mathrm{~Hz}$ \\
Number of modules per arm & $N$ & $2 \mid 1$ \\
Open-circuit voltage & $v_{d c o}$ & $800 \mathrm{~V} \mid 790 \mathrm{~V}$ \\
MPP Voltage & $v_{d c}$ & $700 \mathrm{~V}$ \\
dc-link Capacitance & $C_{d c}$ & $4700 \mu \mathrm{F}$ \\
dc Resistor & $R_{d c}$ & $35 \Omega \mid 38 \Omega$ \\
Switching Frequency & $f_{c}$ & $5200 \mathrm{~Hz} \mid 8200 \mathrm{~Hz}$ \\
\hline Inductance LC Filter & $L_{f}$ & $3 \mathrm{mH}$ \\
Capacitance LC Filter & $C_{f}$ & $-\mid 5 \mu \mathrm{F}$ \\
\hline Transformer Voltage & $V_{T}$ & $400 \mathrm{~V}$ \\
Transformer Power & $P_{T}$ & $2 \mathrm{~kW}$ \\
Inductance Primary Winding & $L_{T 1}$ & $4.7 \mathrm{mH}$ \\
Inductance Secondary Winding & $L_{T 2}$ & $4.2 \mathrm{mH}$ \\
Magnetizing Inductance & $L_{T M}$ & $3.937 \mathrm{H}$ \\
\hline \hline
\end{tabular}

The case of study has been selected as it resembles the experimental setup available in the laboratory, whose results are shown in the next section. This parallelism has permitted the comparison and validation of both the simulated and experimental results.

The dynamic performance of the converter is studied through four different scenarios and their response are shown from Fig.7 to Fig.9. The converter has a nominal power of $8 \mathrm{~kW}$ and each module can generate up to $2 \mathrm{~kW}$. During the first $0.2 \mathrm{~s}$ all modules operate in open-circuit voltage, therefore their $V_{d c}$ are equal to $800 \mathrm{~V}$ and no power is delivered to the grid. This scenario is observed in Fig.7, where the dc average voltage in the upper and lower arm has the same level $(800 \mathrm{~V})$ while the output power is zero. The first power step happens at $\mathrm{t}=0.3 \mathrm{~s}$, in that time, modules in the lower arm decrease their dc voltage reference to $700 \mathrm{~V}$ in order to achieve the maximum power, while modules in the upper arm maintain the $800 \mathrm{~V}$. Fig.7b shows how the average dc voltage decreases to $700 \mathrm{~V}$ with a dynamic response of $0.2 \mathrm{~s}$. The next step happens at $\mathrm{t}=0.9 \mathrm{~s}$, where modules of the upper arm decrease their $\mathrm{dc}$ voltage to generate different power levels. $M_{u 1}$ decreases to

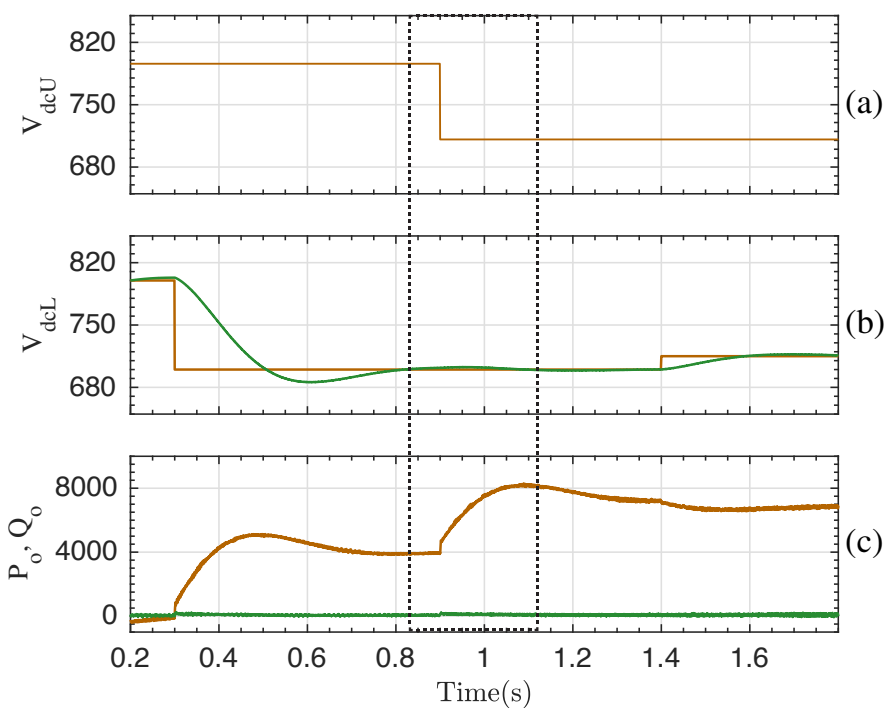

Fig. 7. Dynamic performance of the IMCC. (a) Average dc voltage in the upper arm, (b) Average dc voltage in the lower arm, (c) Active and reactive output power.
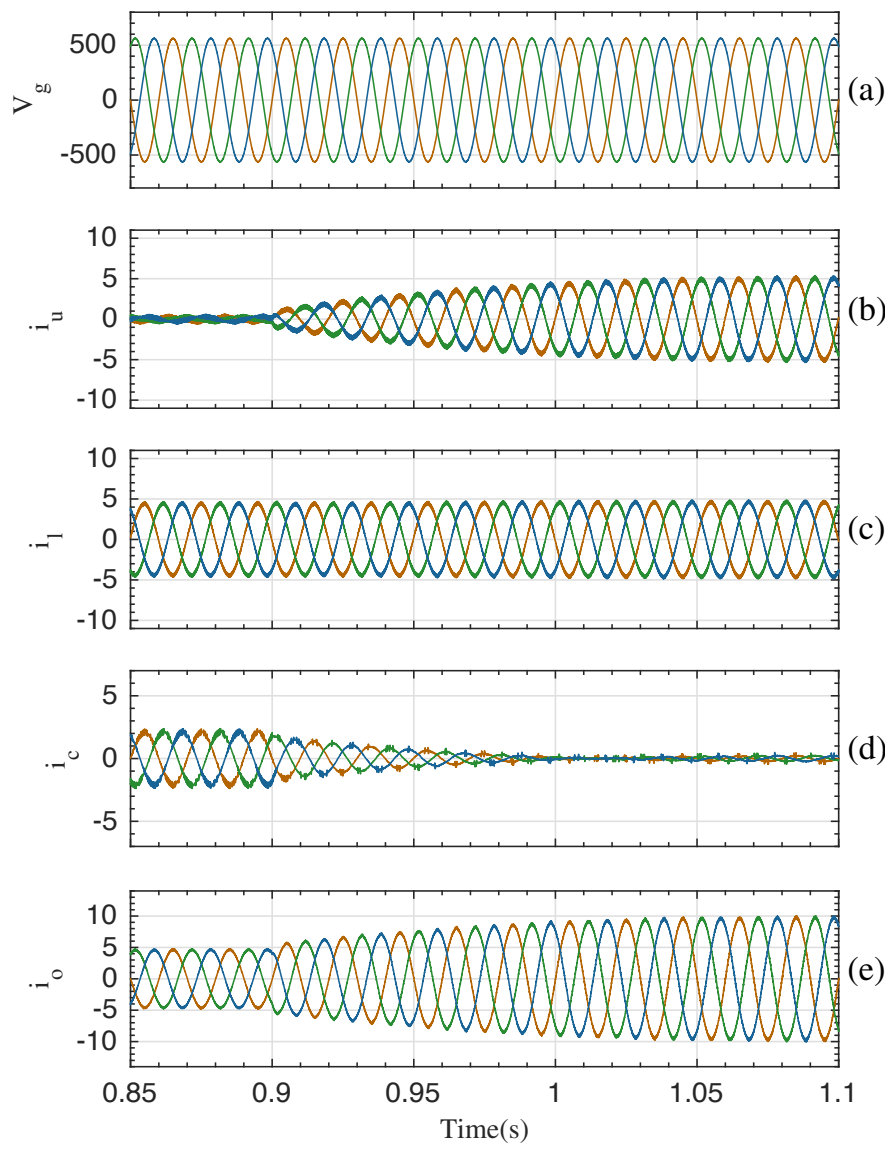

Fig. 8. Dynamic performance of the grid voltage and current waveforms. (a) Grid voltage, (b) Current of the upper arm, (c) Current of the lower arm, (d) Circulating current, (e) Output current.

$700 \mathrm{~V}$ and generates $2 \mathrm{~kW}$, while $M_{u 2}$ decreases to $730 \mathrm{~V}$ and generates $1.43 \mathrm{~kW}$. After the dynamic transient, the converter injects $7.43 \mathrm{~kW}$ to the grid and both arms regulate the average 

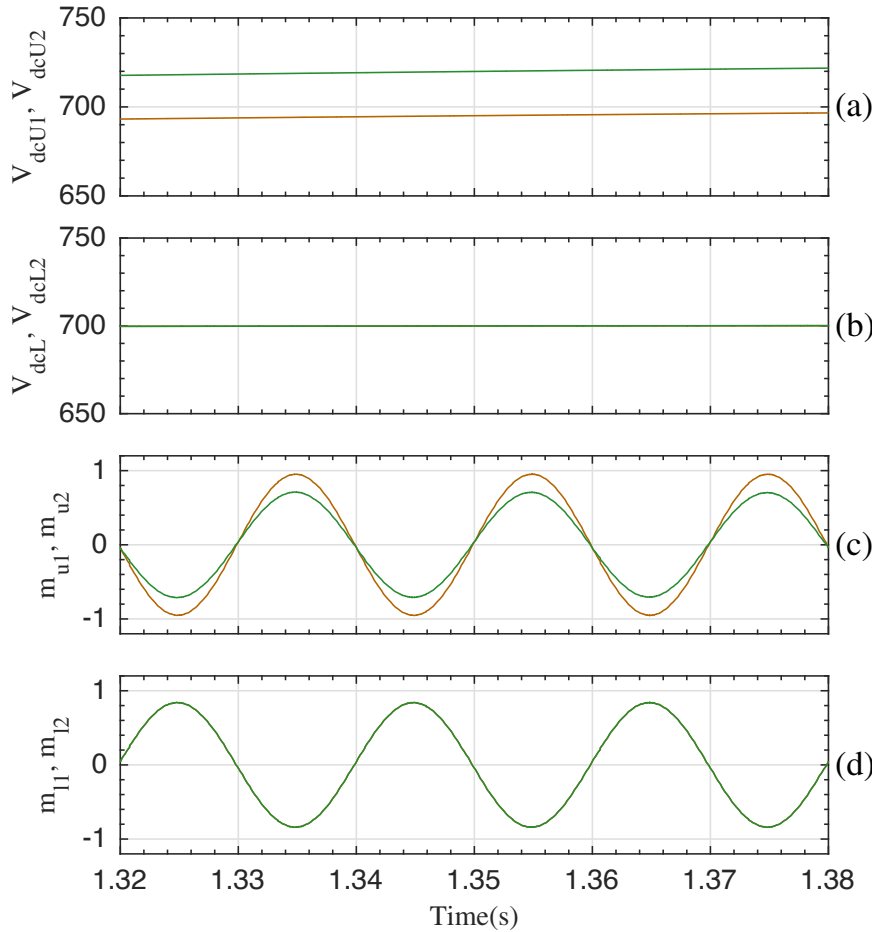

Fig. 9. Voltage balancing response. (a) DC voltages in the upper arm modules, (b) DC voltage in the lower arm modules, (c) Modulation index in the upper arm modules, (d) Modulation index in the lower arm modules.

dc voltage according to their references. To analyze the power unbalance among all modules, at $\mathrm{t}=1.4 \mathrm{~s}$ the voltage reference in $M_{l 1}$ increases to $750 \mathrm{~V}$, this voltage change gives rise to a reduction of the active power and an increase of the average dc voltage in the lower arm.

According to the previous analysis, a power unbalance gives rise to a circulating current in the arms. This scenario can be studied in Fig.8 from the time span marked in Fig.7, where modules $M_{u 1}$ and $M_{u 2}$ decrease their dc voltage to start injecting power to the grid, while modules in the lower arm inject their maximum power from the previous step. Before $\mathrm{t}=$ $0.9 \mathrm{~s}$, none of the upper arm modules produce power, therefore, $i_{u}$ is zero and $i_{l}$ has its nominal value. This situation can be verified in Fig.8b, Fig.8c and Fig.8d respectively, where it is shown the current arm and the circulating current. At $\mathrm{t}=0.9 \mathrm{~s}$, modules of the upper arm decrease their dc voltage to increase the power injected and thus, the circulating current decreases as long as the upper current arm increases.

Finally, in order to validate the performance of the voltage balancing control, Fig.9 shows the dc voltage and the modulation index in all modules. The $30 \mathrm{~V}$ of difference between $M_{u 1}$ and $M_{u 2}$ leads to a $28.5 \%$ of power difference. Therefore, the voltage balancing control increase or decrease the modulation index $m_{u d}$ according to the dc voltage level set by the reference. A lower dc voltage provides a higher power and thus, a higher modulation index amplitude is needed. On the other hand, a higher dc voltage provides a lower power, hence, a lower modulation index amplitude is required to maintain the dc voltage close its reference. In Fig.9c the power unbalance affects the modulation index amplitude between $m_{u 1}$ and $m_{u 2}$,

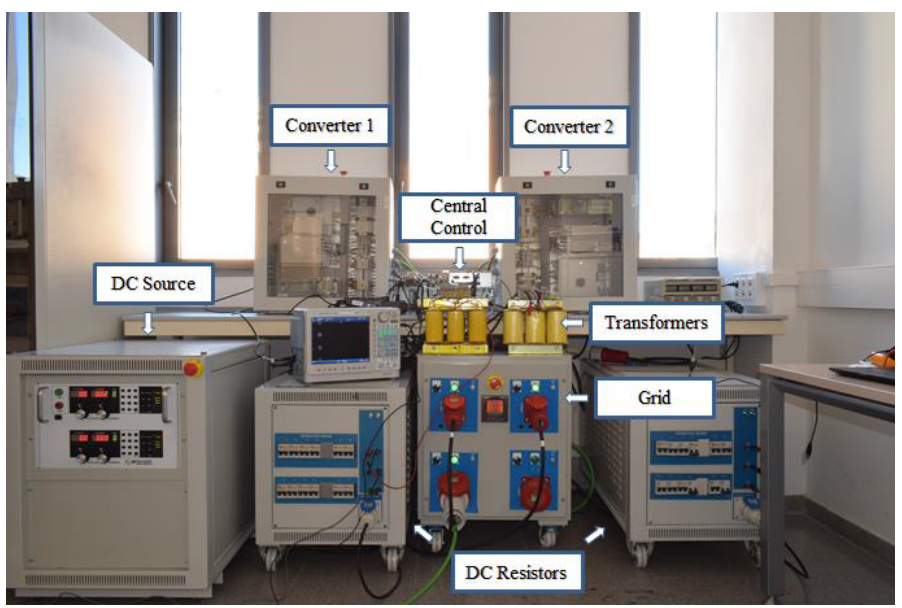

(a)

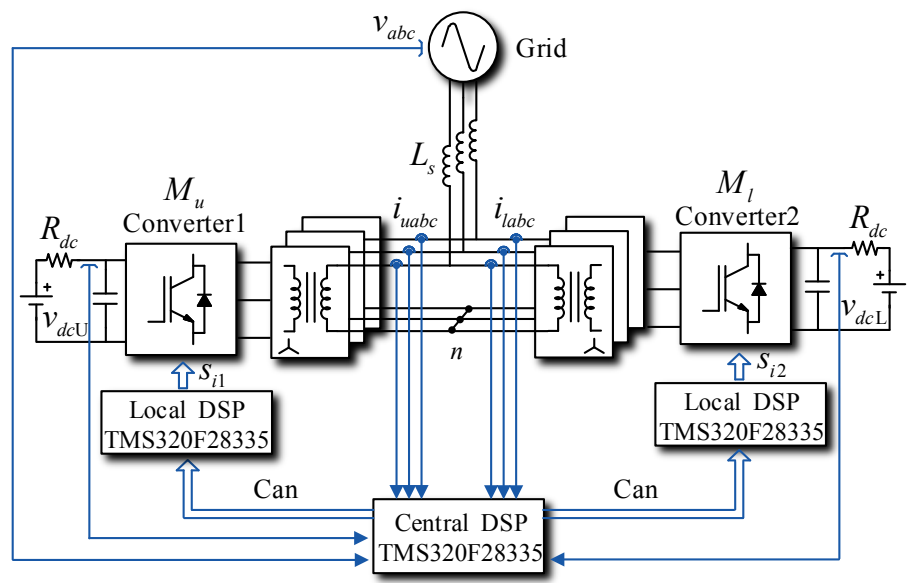

(b)

Fig. 10. Experimental setup. (a) Laboratory layout, (b) Schematic

while Fig.9d shows that $m_{l 1}$ and $m_{l 2}$ do not present any difference since both modules generate the same power.

\section{EXPERIMENTAL RESULTS}

The technical performance of the proposed converter and its associated controller are validated with the hardware setup illustrated in Fig.10. The platform consists of two threephase inverters connected in parallel through low frequency transformers. The converter 1 represents the series connection of modules in the upper arm, while the converter 2 represents the series connection of modules in the lower arm. Therefore, the setup only validates the parallel connection between the arms and the central control required to regulate the circulating and the output current. To operate between the maximum power point and the open circuit voltage, the dc side of each inverter is connected to a dc source in series with a resistor bank.

Since classical low frequency transformers are used, a filter between the inverter and the transformers is required to reduce the high frequency components in the induced voltage and thus, reduce the transformer losses. Regarding the control system, each module has a control board based on a DSP TMS320F28335 to provide protections, adjusts the modulation 


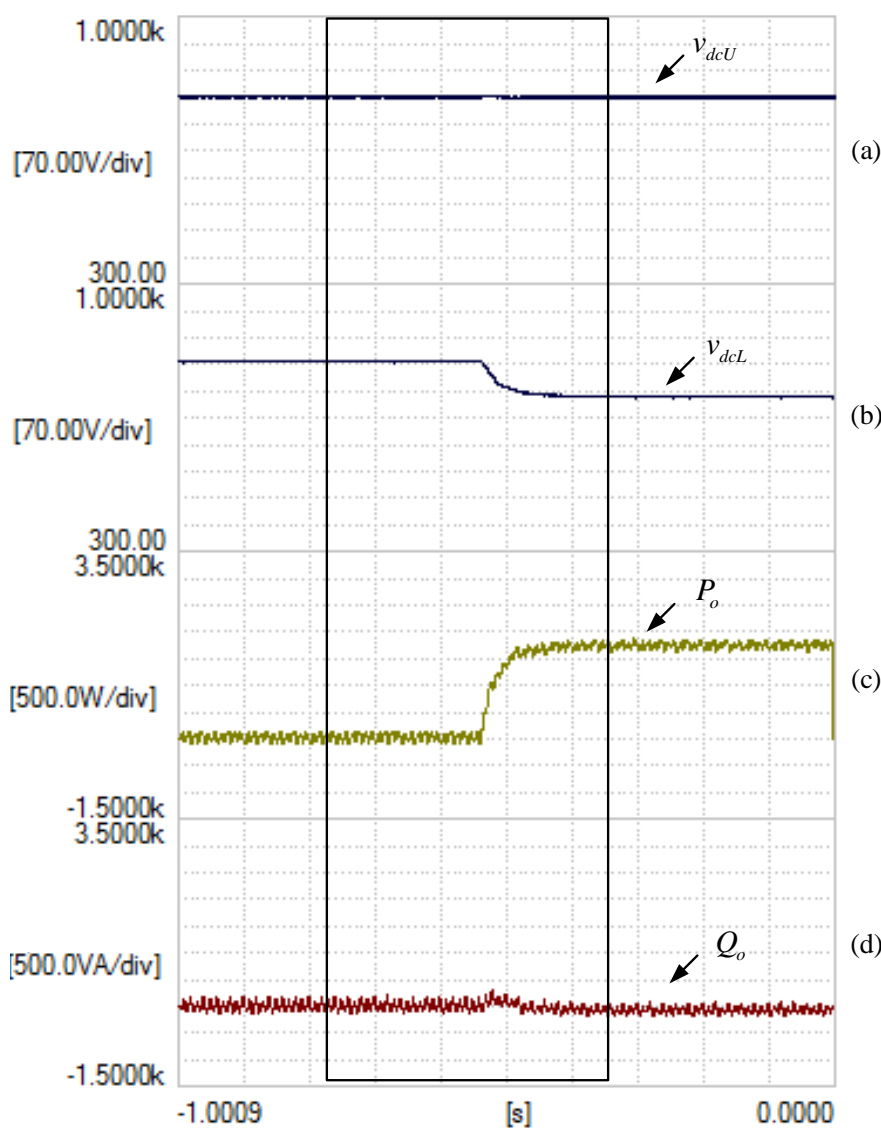

Fig. 11. Dynamic performance of the IMMC under a power change in the lower arm. (a) DC voltage in the upper arm module, (b) DC voltage in the lower arm module, (c) Output active power, (d) Output reactive power.

index and generates the PWM signals. A central DSP measures the current arms and the grid voltage to control the upper and the lower average modulation index, which are sent through a CAN bus to the modules. The parameters of the experimental setup are shown in the right side of Table. I.

To validate the voltage balancing control, a hardware in the loop (HIL) with two modules per arm is used. The setup is based on the Typhoon HIL 402 platform connected to a control board with three DSP TMS320F28335 which are responsible for controlling the dc voltage in each module. An external board with a DSP includes the central control. This board measures the current arms and the grid voltage from the measurement board docked to the Typhoon HIL and set the average modulation index for the upper and lower arm. The communication between the external and the control boards is performed through a CAN bus and the signals are monitored and controlled from a PC station. The subsection power unbalance between modules shows the results with the HIL platform.

\section{A. Power change in the lower arm}

In order to test the central controller, a similar analysis to the one performed in simulations results is studied. As can be seen in Fig.11, when modules operate in open-circuit voltage

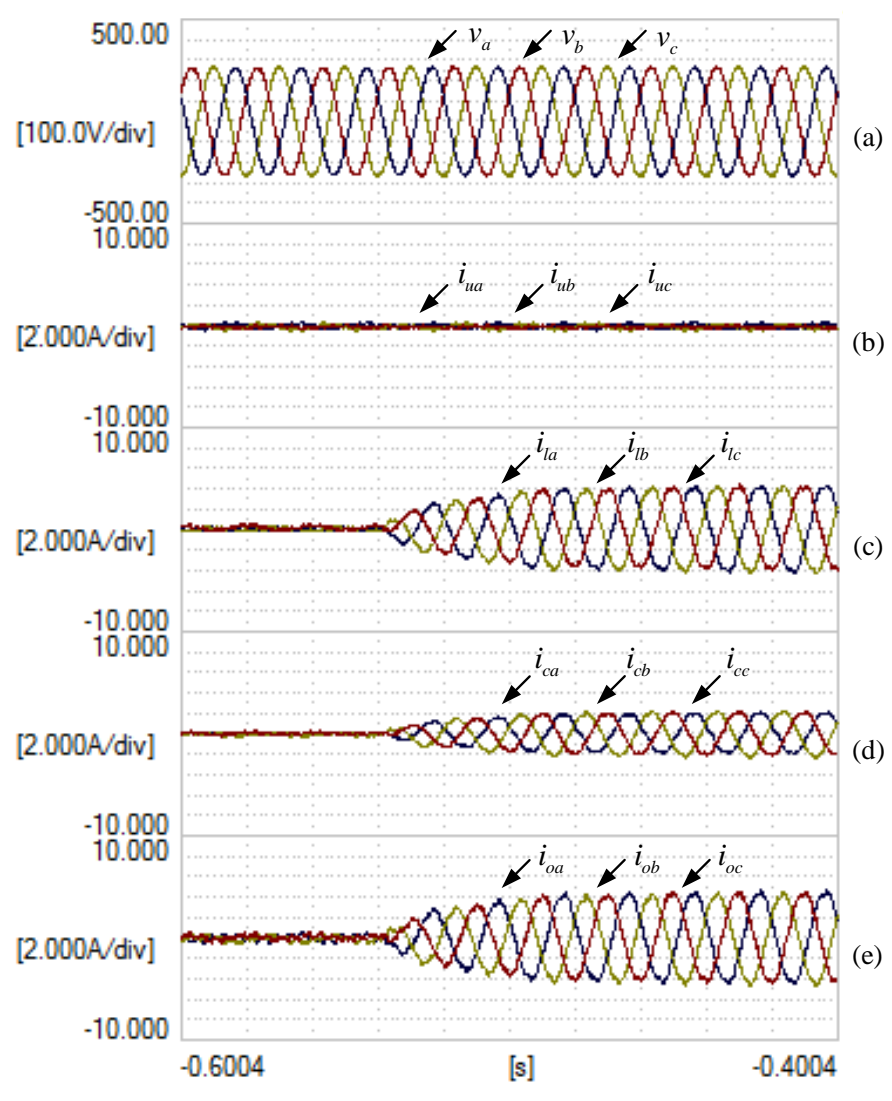

Fig. 12. Voltage and current waveforms under a power change in the lower arm. (a) Grid voltage, (b) Upper arm current, (c) Lower arm current, (d) Circulating current, (e) Output current.

(790V), no active and reactive power is delivered to the grid. However, a voltage reference change in $M_{l}$ gives rise to an increase in the active power. This performance is verified in Fig.11b and Fig.11c where $V_{d c L}$ decreases until 700V, while the active power delivered to the grid increases up to $1.85 \mathrm{~kW}$. In case of the reactive power, there is no power since its reference is set to zero.

Following the previous analysis, the voltage and current waveforms studied from the highlighted windows in Fig.11 are shown in Fig.12. Before the dc voltage changes, no power is generated from any module. Due to this, there is no circulating or output current in the converter. However, as soon as the dc voltage in the lower arm module decreases, its active power increase and thus, the unbalance between $M_{u}$ and $M_{l}$ gives rise to an increase in the circulating current. According to the expression (5b), this current is half of the current arm, which is verified in Fig.12c and Fig.12d respectively. Since, the dc voltage $V_{d c U}$ does not change, the upper current arm shown in Fig. 12b is zero. In the case of the grid voltage, there is no disturbance because the converter is connected to a stiff grid.

\section{B. Power change in the upper arm}

The second test shown in Fig.13 and Fig.14 analyzes the dynamic performance of the converter under a power increase 


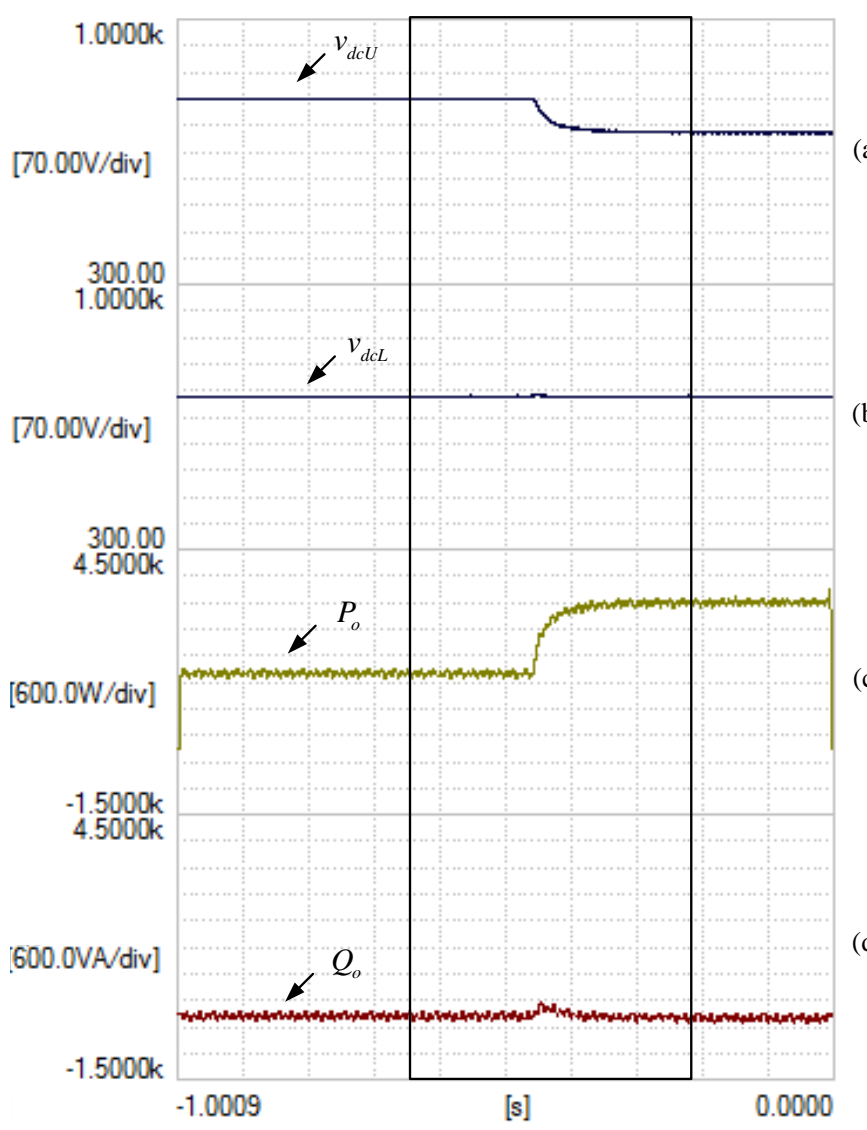

Fig. 13. Dynamic performance of the IMMC under a power change in the upper arm. (a) DC voltage in the upper arm module, (b) DC voltage in the lower arm module, (c) Output active power, (d) Output reactive power.

in the upper arm. Before the dc voltage in $M_{u}$ decreases, the current in the upper arm is zero, therefore, the active power $P_{o}$ depends only on $M_{l}$. The situation changes when $V_{d c U}$ decreases to $700 \mathrm{~V}$, since the power in the upper arm increases to generate the same power level as the lower arm, the current $i_{u}$ increases and the circulating current decreases to zero. The current waveform of $i_{u}$ and $i_{c}$ are shown in Fig.14b and Fig.14d respectively, which demonstrate how the circulating current decreases as long as $i_{u}$ increases. Furthermore, the dynamic response of the output current is shown in Fig.14e. After the dynamic transient, $M_{u}$ generates the same power level as $M_{l}$, and the current $i_{o}$ increases twice.

\section{Power unbalance between modules of the upper arm}

The power unbalance between modules in the upper arm is validated through the hardware in the loop platform. Since the series connection of modules increases the ac voltage, to maintain the same grid voltage level used in the experimental setup $(320 \mathrm{~V})$, the dc voltage in each module has been reduced. The open-circuit voltage is $490 \mathrm{~V}$ and the voltage at maximum power is $364 \mathrm{~V}$. Thanks to the voltage balancing control introduced in each module, Fig.15a shows how the voltage difference between $V_{d c U 1}$ and $V_{d c U 2}$ is controlled at different levels, while $V_{d c L 1}$ and $V_{d c L 2}$ presented in Fig.15b maintain

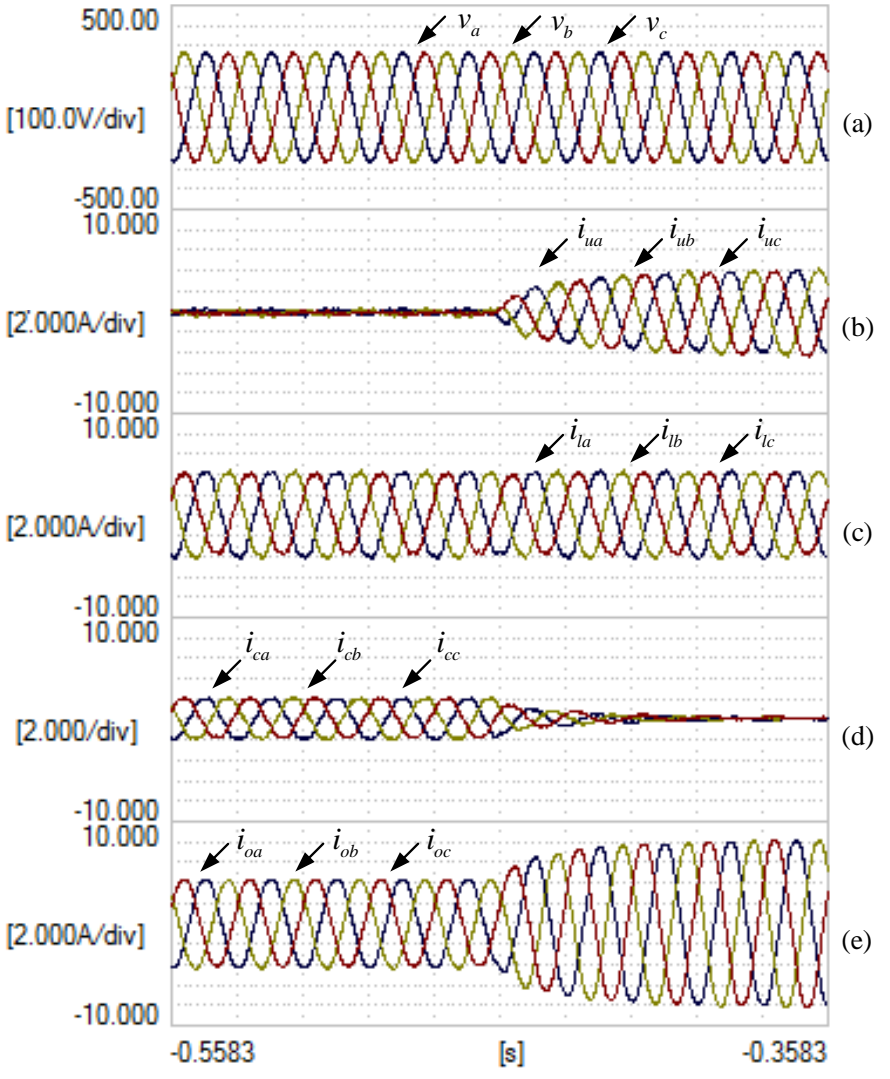

Fig. 14. Voltage and current waveforms under a power change in the upper arm. (a) Grid voltage, (b) Upper arm current, (c) Lower arm current, (d) Circulating current, (e) Output current.

the same level to provide the maximum power available. The voltage difference between $V_{d c U 1}$ and $V_{d c U 2}$ gives rise to a power difference between both arms, which is appreciated in the current arms shown in Fig.15c and Fig.15d, where the current in the upper arm has a smaller amplitude compared to the current in the lower arm. The power generated by the modules in the upper arm is $1 \mathrm{~kW}$ and $2 \mathrm{~kW}$ respectively, meanwhile the lower arm modules generate $2 \mathrm{~kW}$. The power difference between the modules is directly related to the $\mathrm{dc}$ voltage difference.

\section{CONCLUSION}

A novel topology based on the CTMI and the MMC configuration for utility-scale PV plants has been presented in this paper. The galvanic isolation provided by low frequency transformers allows the converter to connect isolated dc sources and thus, remove the problems related to floating voltages. Moreover, the possibility of different transformation ratios as well as the capability of connecting several modules in series permit to increase the number of voltage levels and connect the converter to medium voltage applications. This configuration has proven to be useful in systems where low frequency transformers are essential. To prove its feasibility, simulations results were conducted with four modules, while the experimental setup was scaled with two modules. The 


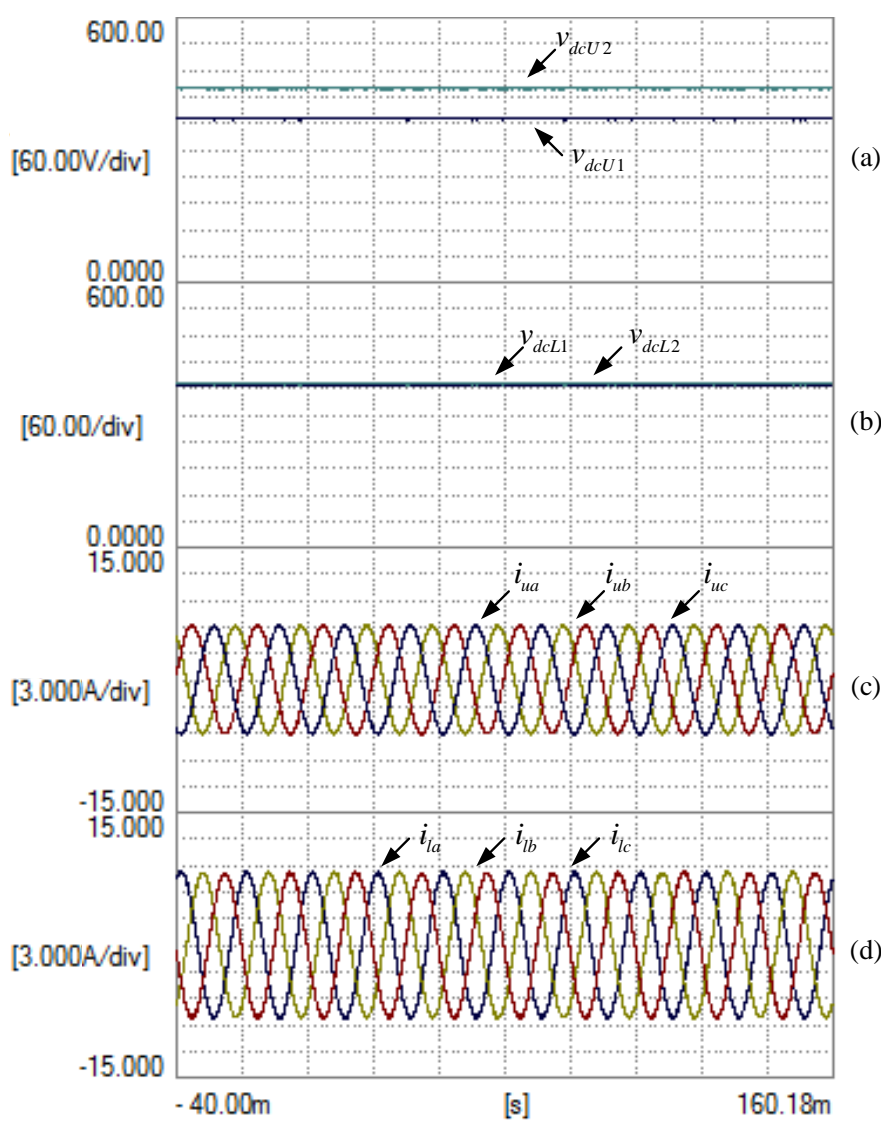

Fig. 15. DC voltage and current arms waveforms under a power unbalance between modules. (a) DC voltages in the upper arm, (b) DC voltages in the lower arm, (c) Upper current arm, (d) Lower current arm.

results obtained in simulation confirms that the converter is able to operate with power unbalances between arms and modules. In addition, the experimental setup validates the technical aspect of the converter and its control structure. The main purpose of the setup was to analyze the central control and the capability of operating under power unbalance conditions between the arms. The results show that a circulating current arises when the converter generates different power levels, which is used to compensate effectively this power unbalance. Moreover, a HIL platform is introduced to validate the power unbalance between modules of one arm, where it is verified the correct operation of the voltage balancing control.

\section{ACKNOWLEDGMENT}

This work has been supported by the Spanish Ministry of Economy and Competitiveness under the projects ENE201679493-R and ENE2017-88889-C2-1-R. Any opinions, findings and conclusions or recommendations expressed in this material are those of the authors and do not necessarily reflect those of the host institutions or founders

\section{REFERENCES}

[1] F. Blaabjerg, R. Teodorescu, M. Liserre and A. V. Timbus, "Overview of Control and Grid Synchronization for Distributed Power Generation Systems," in IEEE Transactions on Industrial Electronics, vol. 53, no. 5, pp. 1398-1409, Oct. 2006
[2] J. M. Carrasco et al., "Power-Electronic Systems for the Grid Integration of Renewable Energy Sources: A Survey," in IEEE Transactions on Industrial Electronics, vol. 53, no. 4, pp. 1002-1016, June 2006.

[3] P. Bresesti, W. L. Kling, R. L. Hendriks and R. Vailati, "HVDC Connection of Offshore Wind Farms to the Transmission System," in IEEE Transactions on Energy Conversion, vol. 22, no. 1, pp. 37-43, March 2007.

[4] E. Serban, M. Ordonez and C. Pondiche, "DC-Bus Voltage Range Extension in 1500 V Photovoltaic Inverters," in IEEE Journal of Emerging and Selected Topics in Power Electronics, vol. 3, no. 4, pp. 901-917, Dec. 2015.

[5] S. Kouro et al., "Recent Advances and Industrial Applications of Multilevel Converters," in IEEE Transactions on Industrial Electronics, vol. 57, no. 8, pp. 2553-2580, Aug. 2010.

[6] L. G. Franquelo, J. Rodriguez, J. I. Leon, S. Kouro, R. Portillo and M. A. M. Prats, "The age of multilevel converters arrives," in IEEE Industrial Electronics Magazine, vol. 2, no. 2, pp. 28-39, June 2008.

[7] S. Kouro, K. Asfaw, R. Goldman, R. Snow, B. Wu and J. Rodríguez, "NPC multilevel multistring topology for large scale grid connected photovoltaic systems," The 2nd International Symposium on Power Electronics for Distributed Generation Systems, Hefei, China, 2010, pp. 400-405.

[8] G. Gateau, M. Fadel, P. Maussion, R. Bensaid and T. A. Meynard, "Multicell converters: active control and observation of flying-capacitor voltages," in IEEE Transactions on Industrial Electronics, vol. 49, no. 5, pp. 998-1008, Oct 2002.

[9] E. Villanueva, P. Correa, J. Rodriguez and M. Pacas, "Control of a Single-Phase Cascaded H-Bridge Multilevel Inverter for Grid-Connected Photovoltaic Systems," in IEEE Transactions on Industrial Electronics, vol. 56, no. 11, pp. 4399-4406, Nov. 2009.

[10] M. Saeedifard and R. Iravani, "Dynamic Performance of a Modular Multilevel Back-to-Back HVDC System," in IEEE Transactions on Power Delivery, vol. 25, no. 4, pp. 2903-2912, Oct. 2010. doi: 10.1109/TPWRD.2010.2050787

[11] R. Marquardt, "Modular Multilevel Converter: An universal concept for HVDC-Networks and extended DC-Bus-applications," The 2010 International Power Electronics Conference - ECCE ASIA -, Sapporo, 2010, pp. 502-507.

[12] T. Urakabe, K. Fujiwara, T. Kawakami and N. Nishio, "High efficiency power conditioner for photovoltaic power generation system," The 2010 International Power Electronics Conference - ECCE ASIA -, Sapporo, 2010, pp. 3236-3240.

[13] W. Zhao, H. Choi, G. Konstantinou, M. Ciobotaru and V. G. Agelidis, "Cascaded H-bridge multilevel converter for large-scale PV gridintegration with isolated DC-DC stage," 2012 3rd IEEE International Symposium on Power Electronics for Distributed Generation Systems (PEDG), Aalborg, 2012, pp. 849-856.

[14] M. A. Perez, D. Arancibia, S. Kouro and J. Rodriguez, "Modular multilevel converter with integrated storage for solar photovoltaic applications," IECON 2013 - 39th Annual Conference of the IEEE Industrial Electronics Society, Vienna, 2013, pp. 6993-6998.

[15] A. A. Gandomi, S. Saeidabadi, S. H. Hosseini, E. Babaei and M. Sabahi, "Transformer-based inverter with reduced number of switches for renewable energy applications," in IET Power Electronics, vol. 8, no. 10, pp. 1875-1884, 102015.

[16] M. R. Banaei, H. Khounjahan and E. Salary, "Single-source cascaded transformers multilevel inverter with reduced number of switches," in IET Power Electronics, vol. 5, no. 9, pp. 1748-1753, November 2012.

[17] A. K. Panda and Y. Suresh, "Performance of cascaded multilevel inverter by employing single and three-phase transformers," in IET Power Electronics, vol. 5, no. 9, pp. 1694-1705, November 2012.

[18] Feel-soon Kang, Modified multilevel inverter employing half- and fullbridge cells with cascade transformer and its extension to photovoltaic power generation, Electric Power Systems Research, Volume 80, Issue 12, 2010, Pages 1437-1445.

[19] J. S. Lee, H. W. Sim, J. Kim and K. B. Lee, "Combination Analysis and Switching Method of a Cascaded H-Bridge Multilevel Inverter Based on Transformers With the Different Turns Ratio for Increasing the Voltage Level," in IEEE Transactions on Industrial Electronics, vol. 65, no. 6, pp. 4454-4465, June 2018.

[20] Feel-soon Kang, Su Eog Cho, Sung-Jun Park, Cheul-U Kim, Toshifumi Ise, A new control scheme of a cascaded transformer type multilevel PWM inverter for a residential photovoltaic power conditioning system, Solar Energy, Volume 78, Issue 6, 2005, Pages 727-738,

[21] H. Khoun jahan, K. Zare and M. Abapour, "Verification of a Low Component Nine-Level Cascaded-Transformer Multilevel Inverter in Grid- 
Tied Mode," in IEEE Journal of Emerging and Selected Topics in Power Electronics, vol. 6, no. 1, pp. 429-440, March 2018.

[22] S. G. Song, F. S. Kang and S. Park, "Cascaded Multilevel Inverter Employing Three-Phase Transformers and Single DC Input," in IEEE Transactions on Industrial Electronics, vol. 56, no. 6, pp. 2005-2014, June 2009.

[23] C. Verdugo, J. I. Candela, F. Blaabjerg and P. Rodriguez, "Model and control of the isolated multi-modular converter," IECON 2017 - 43rd Annual Conference of the IEEE Industrial Electronics Society, Beijing, 2017, pp. 1286-1292.

[24] C. D. Fuentes, C. A. Rojas, H. Renaudineau, S. Kouro, M. A. Perez and T. Meynard, "Experimental Validation of a Single DC Bus Cascaded H-Bridge Multilevel Inverter for Multistring Photovoltaic Systems," in IEEE Transactions on Industrial Electronics, vol. 64, no. 2, pp. 930-934, Feb. 2017.

[25] C. Verdugo, S. Kouro, C. Rojas and T. Meynard, "Comparison of singlephase T-type multilevel converters for grid-connected PV systems," 2015 IEEE Energy Conversion Congress and Exposition (ECCE), Montreal, QC, 2015, pp. 3319-3325.

[26] Amirnaser, Y. and Reza, Iravani, "Voltage - Sourced Converters in Power Systems: Modeling, Control, and Applications", 2012, IEEE Press

[27] Design, Control and Application of Modular Multilevel Converters for HVDC Transmission Systems. / Sharifabadi, Kamran; Harnefors, Lennart; Nee, Hans-Peter; Norrga, Staffan ; Teodorescu, Remus. Wiley-IEEE press, 2016. 386 p.

[28] P. Rodriguez, J. Pou, J. Bergas, J. I. Candela, R. P. Burgos and D. Boroyevich, "Decoupled Double Synchronous Reference Frame PLL for Power Converters Control," in IEEE Transactions on Power Electronics, vol. 22, no. 2, pp. 584-592, March 2007.

[29] C. Verdugo, S. Kouro, M. A. Perez, M. Malinowski and T. Meynard, "Series-connected T-type Inverters for single-phase grid-connected Photovoltaic Energy System," IECON 2013 - 39th Annual Conference of the IEEE Industrial Electronics Society, Vienna, 2013, pp. 7021-7027.

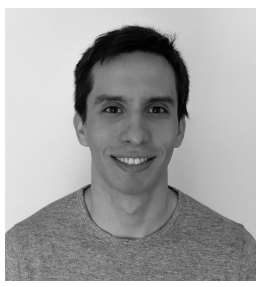

Cristian Verdugo (S'18) was born in Santiago, Chile, in 1989. He received the B.Sc. and M.Sc. degrees in Electronics Engineering from the Technical University Federico Santa Maria, Valparaiso, Chile, in 2012 and 2014, respectively. He is currently working toward his Ph.D. in Electrical Engineering in the Research Center on Renewable Electrical Energy Systems at the Universitat Politècnica de Catalunya (UPC).

His research interests include the control and the level converters and HVDC applications. topologies of photovoltaic plants, control of multi-

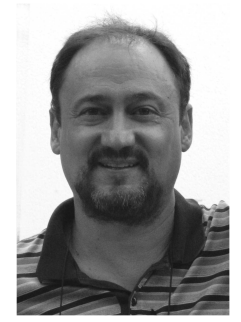

Jose Ignacio Candela (S'99-M'04) received the B.S. and M.S. degrees in industrial engineering and the $\mathrm{Ph} . \mathrm{D}$. degree in electrical engineering from the Technical University of Catalunya (UPC), Barcelona, Spain, in 1987, 2000, and 2009, respectively.

In 1990, he became an Assistant Professor at UPC, where he later advanced to Associate Professor in 1993. He is currently part of the research group on Renewable Electrical Energy Systems, Department of Electrical Engineering. He has authored or coauthored more than 30 published technical papers, and holds several patents. His current research interests include power conditioning, integration of distributed energy systems, and the control of grid-connected power converters. Dr Candela is a member of the IEEE Power Electronics Society, the IEEE Industrial Electronics Society, and the IEEE Industry Application Society.

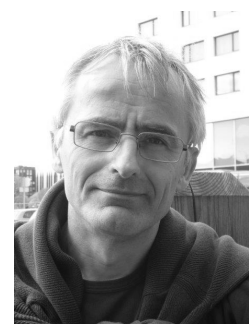

Frede Blaabjerg (S'86-M'88-SM'97-F'03) was with ABB-Scandia, Randers, Denmark, from 1987 to 1988 . From 1988 to 1992 , he got the $\mathrm{PhD}$ degree in Electrical Engineering at Aalborg University in 1995. He became an Assistant Professor in 1992, an Associate Professor in 1996, and a Full Professor of power electronics and drives in 1998. From 2017 he became a Villum Investigator. $\mathrm{He}$ is honoris causa at University Politehnica Timisoara (UPT), Romania and Tallinn Technical University (TTU) in Estonia.

His current research interests include power electronics and its applications such as in wind turbines, PV systems, reliability, harmonics and adjustable speed drives. He has published more than 600 journal papers in the fields of power electronics and its applications. He is the co-author of four monographs and editor of ten books in power electronics and its applications.

He has received 30 IEEE Prize Paper Awards, the IEEE PELS Distinguished Service Award in 2009, the EPE-PEMC Council Award in 2010, the IEEE William E. Newell Power Electronics Award 2014 and the Villum Kann Rasmussen Research Award 2014. He was the Editor-in-Chief of the IEEE TRANSACTIONS ON POWER ELECTRONICS from 2006 to 2012. He has been Distinguished Lecturer for the IEEE Power Electronics Society from 2005 to 2007 and for the IEEE Industry Applications Society from 2010 to 2011 as well as 2017 to 2018. In 2019-2020 he serves a President of IEEE Power Electronics Society. He is Vice-President of the Danish Academy of Technical Sciences too. He is nominated in 2014-2018 by Thomson Reuters to be between the most 250 cited researchers in Engineering in the world.

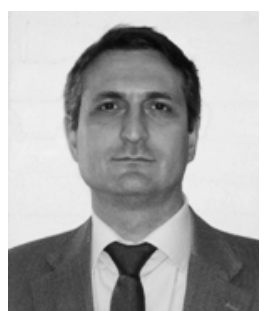

Pedro Rodriguez (F'13) received the M.Sc. and $\mathrm{Ph} . \mathrm{D}$. degrees in electrical engineering from the Technical University of Catalonia (UPC), Barcelona, Spain, in 1989 and 2005, respectively.

In 1990, he joined UPC as an Assistant Professor, and still collaborates with UPC as a part-time Professor and as a Director of the Research Center on Renewable Electrical Energy Systems. In 2005, he was a Visiting Researcher with the Center for Power Electronics Systems, Virginia Polytechnic Institute and State University, Blacksburg, VA, USA. In 2006 and 2007, he was a Postdoctoral Researcher with the Department of Energy Technology, Aalborg University, Aalborg, Denmark, where from 2007 to 2011 , he was a Co-Supervisor of the Vestas Power Program. From 2011 to 2017, he was the Director of Technology in the area of power systems with Abengoa Research, Seville, Spain. In 2017, he joined the Loyola University Andalucía, Seville, as a Full Professor and Director of LoyolaTech. He is one of the 250 top worldwide Highly Cited Researchers in Engineering (2017), published by ISI Thomson Reuters. He has co-authored one Wiley-IEEE book, over 100 papers in ISI technical journals, and around 300 papers in conference proceedings. He is the holder of 14 licensed patents. His current research interests include distributed power systems, flexible transmission systems, and power conversion

Dr. Rodriguez is an Associate Editor of the IEEE TRANSACTIONS ON POWER ELECTRONICS, and a member of the Sustainability and Renewable Energy Committee of the IEEE Industry Applications Society and the Renewable Energy Systems Technical Committee of the IEEE Industrial Electronics Society. 